\title{
Determination of the Concentration of Diallyl Trisulfide in Rat Whole Blood Using Gas Chromatography with Electron-Capture Detection and Identification of Its Major Metabolite with Gas Chromatography Mass Spectrometry
}

\author{
Xuehui Sun, ${ }^{a, b}$ Tao GuO, ${ }^{*, a}$ Jin HE, ${ }^{a}$ Minghong ZHAO, ${ }^{a}$ \\ Ming YAN, ${ }^{a}$ Fude CUI, ${ }^{b}$ and Yihui DENG ${ }^{b}$ \\ ${ }^{a}$ General Hospital of Shenyang Military Region, Shenyang 110016, China, and \\ ${ }^{b}$ Shenyang Pharmaceutical University, Shenyang 110016, China
}

(Received February 17, 2006; Accepted April 8, 2006)

\begin{abstract}
A simple, rapid, and sensitive procedure has been developed using gas chromatography with electron-capture detection to measure diallyl trisulfide levels in rat blood. Blood samples were acidified, and the analyte was extracted with hexane, and then degradation was stopped with acetonitrile before gas chromatographic separation. Two calibration curves were linear over the range of $10-500 \mathrm{ng} / \mathrm{ml}$ and $0.2-20 \mu \mathrm{g} / \mathrm{ml}$, with typical $r$ values of 0.9986 and 0.9993 , respectively. The structure of its major metabolite was confirmed using combined gas chromatography-mass spectrometry. The limit of detection was less than $10 \mathrm{ng} / \mathrm{ml}$, and the assay was highly reproducible, giving peaks with excellent chromatographic properties. The method is suitable for pharmacokinetic and therapeutic purposes.
\end{abstract}

Key words_—_ diallyl trisulfide; diallyl disulfide; electron-capture gas chromatography; gas chromatography-mass spectrometry

\section{INTRODUCTION}

Garlic (Allium sativum L.) is widely used as a foodstuff and is known to exhibit a variety of biological activities including hypolipidemic, antithrombotic, antiatherosclerotic, antimutagenic, anticarcinogenic, and antibacterial effects. ${ }^{1)}$ It contains a variety of volatile oils that are pharmacologically active ${ }^{2-6}$ ) and have been identified by gas chromatography. ${ }^{7)}$ Among these organosulfur compounds (OSCs), diallyl sulfide (DAS), diallyl disulfide (DADS), and diallyl trisulfide (DATS) are the three major components. DATS, an oil-soluble constituent of garlic, has the same biological activities and can be obtained by chemical synthesis. ${ }^{8,9)}$

A great deal of effort has been devoted to measuring the levels of some OSCs and metabolites in vivo. Lachmann et al. ${ }^{10)}$ investigated the pharmacokinetics of the garlic constituents alliin, allicin, and vinyldithiine using ${ }^{35} \mathrm{~S}$ labeling, but this could not distinguish between drug antetype and metabolites and was harmful to volunteers. Arnault et al. ${ }^{11)}$ developed a new ion-pair HPLC method to quantify OSCs for evaluation of garlic therapeutic potential and for validation of a new formulation, while Rosen et al. ${ }^{12}$ de-

\footnotetext{
*e-mail: sy-guotao@263.net
}

termined allicin, S-allylcysteine, and volatile metabolites of garlic in breath, plasma, or simulated gastric fluids using HPLC, gas chromatography (GC) or HPLC-mass spectrometry and GC-mass spectrometry (MS). However, these methods lack the sensitivity and selectivity required for directly determining the contents of DATS in a small part of a sample in vivo and are laborious and time-consuming. Mass spectrometry is expensive and hence often not readily accessible in general laboratories.

The objective of the present investigation was to establish a fully validated GC-electron-capture detection (ECD) method with a quantification limit sufficiently low to support pharmacokinetic and bioequivalence studies of DATS and also allow quantification of large numbers of blood samples. The method reported in this paper is an accurate and precise GC-ECD method to quantify blood concentrations of DATS using liquid-liquid extraction. This method has been fully validated in accordance with US Food and Drug Administration (FDA) guidelines. ${ }^{13)}$

\section{MATERIALS AND METHODS}

Materials Drug standards of DATS were purchased from Shangdong Jinxiang Food and Medicine Co., Ltd. (the original purity is about $90 \%$, but this 
can be increased to $97 \%$ after refining). DADS (purity $80 \%$, increased to $99 \%$ after refining) was obtained from Sigma-Aldrich (Steinheim, Belgium), and Allitride Injection from Jinan Limin Pharmaceutical Co., Ltd. (Jinan, China). In addition, 1,4dichloronitrobenzene [internal standard, IS] and other organic solvents used were all of analytical-reagent grade (Shenyang Chemical Reagents Co., Ltd., Shenyang, China).

Equipments and Method Development Analyses were performed on a Agilent $6890 \mathrm{~N}$ gas chromatograph equipped with an ${ }^{63} \mathrm{Ni}$ electron-capture detector. A fused-silica capillary column $(30 \mathrm{~m} \times 0.25$ $\mathrm{mm}$ i.d.) was used coated with a $0.25 \mu \mathrm{m}$ thick film of $5 \%$ phenyl methyl siloxane (Agilent, USA) as the stationary phase. The conditions for gas chromatographic separation were as follows. The oven temperature was set at $120^{\circ} \mathrm{C}$ and maintained for $15 \mathrm{~min}$. Temperatures at the injection port and detector were $220^{\circ} \mathrm{C}$ and $300^{\circ} \mathrm{C}$, respectively. Ultrapure nitrogen (purity $>99.999 \%$, Shenyang Kerui Special Gases Co., Ltd., Shenyang, China) was used as a carrier gas and make-up gas at flow rate of $1 \mathrm{ml} / \mathrm{min}$ and $60 \mathrm{ml} /$ min, respectively. All injections were carried out in the split-injection mode with a split ratio of $1: 10$.

To confirm the structure of the major metabolite of DATS, GC-MS was carried out using an Angilent $6890 \mathrm{~N}$ gas chromatograph linked to a $5973 \mathrm{~N}$ massselective detector. The ionization mode was electron impact (EI) with a $70-\mathrm{eV}$ electron beam, and the mass range of the scan mode was $m / z$ 35-550. The capillary column used was DB-5 (Agilent, USA), with a carrier gas flow rate of $1.0 \mathrm{ml} / \mathrm{min}(\mathrm{He})$, and the injection was in the split mode $(1: 10)$. The temperature programming of the column was as follows: $80-225^{\circ} \mathrm{C}$ at $8^{\circ} \mathrm{C} / \mathrm{min}$ and then holding for $5 \mathrm{~min}$. The temperature of the injector and transfer line were 220 and $260^{\circ} \mathrm{C}$, respectively.

Procedure for the Determination of DATS in Blood Samples A 0.2-ml volume of rat blood was transferred to a 5-ml glass test tube, and then $20 \mu \mathrm{l}$ of $10 \%(\mathrm{v} / \mathrm{v})$ dilute hydrochloric acid was added, followed by brief mixing on a YKH-II vortex mixer (Jiangxi Medical Appliance Co., Ltd, Jiangxi, China). Next, $0.2 \mathrm{ml}$ acetonitrile containing IS (100 ng/ $\mathrm{ml}$ or $2 \mu \mathrm{g} / \mathrm{ml}$ ) was added and the tube was vortexed immediately. Hexane $(0.4 \mathrm{ml}$ or $1 \mathrm{ml})$ was added, the tube was capped and shaken vigorously for $0.5 \mathrm{~min}$, then centrifuged at $2000 \times \mathrm{g}$ for $5 \mathrm{~min}$ in a bench top centrifuge (TDL-5, Shanghai Anting Medical Appliance Co., Ltd., Shanghai, China). Following this, 1 $\mu \mathrm{l}$ of the organic layer was used for GC analysis.

Preparation of Calibration Standards Stock solutions of DATS $(1 \mathrm{mg} / \mathrm{ml})$, its metabolites, and internal standard $(100 \mathrm{ng} / \mathrm{ml}$ or $2 \mu \mathrm{g} / \mathrm{ml})$ were prepared in methanol. Working solutions were further diluted with methanol and stored at $4{ }^{\circ} \mathrm{C}$. The standard curves for DATS $(10-500 \mathrm{ng} / \mathrm{ml}$, or $0.2-20 \mu \mathrm{g} /$ $\mathrm{ml}$ ) were freshly prepared on the day of analysis by adding $10 \mu \mathrm{l}$ of the appropriate working solutions to $0.2 \mathrm{ml}$ of drug-free rat blood. Calibration curve I was obtained with standards at final concentrations of 10 , 20, 40, 100, 200 and $500 \mathrm{ng} / \mathrm{ml}$ in rat blood and calibration curve II was obtained with standards at final concentrations of $0.2,0.5,1,5,10$, and $20 \mu \mathrm{g} / \mathrm{ml}$. Quality control (QC) samples were prepared in bulk at concentrations of 20,100 , and $400 \mathrm{ng} / \mathrm{ml}$ and 0.2 , 5 , and $20 \mu \mathrm{g} / \mathrm{ml}$ of DATS and stored at $4^{\circ} \mathrm{C}$.

Accuracy, Precision, Lower Limit of Quantification, and Recovery The accuracy and betweenand within-day precisions of the method were determined according to the FDA guidelines for bioanalytical method validation. ${ }^{13)}$ Three replicate spiked blood samples were subjected to between- and within-day assays at different low, medium, and high concentrations $(20,100,400 \mathrm{ng} / \mathrm{ml}$ and $0.2,1,10 \mu \mathrm{g} / \mathrm{ml})$ of each analyte. The concentrations were calculated using calibration curves prepared and analyzed in the same run. Accuracy was calculated as the deviation of the mean from the nominal concentration. Betweenand within-day precision values were expressed as the relative standard deviation (RSD) of each calculated concentration. For the concentration to be accepted as the limit of quantification (LOQ), the percentage deviation from the nominal concentration (accuracy) and the relative standard deviation had to be $\pm 20 \%$ and $<20 \%$, respectively, under the condition of at least five-fold the response compared with the blank response.

Stability of DATS in Rat Blood Blood samples at a final concentration of $1 \mu \mathrm{g} / \mathrm{ml}$ of DATS were prepared for quantification after storage under different conditions, such as room temperature, $-20^{\circ} \mathrm{C}$, and after three freeze-thaw cycles. The same samples after precipitation with acetonitrile and extraction with hexane were quantitated by the previously mentioned method.

Application of the Method Six Wistar rats (260 
$-300 \mathrm{~g}$ ) were used in the experiments. The animals were housed in hanging wire cages with free access to food and water and a $12 \mathrm{~h}$ light/dark cycle (lights on at $06: 00)$ at a temperature of $19-20^{\circ} \mathrm{C}$. The experimental protocol was designed according to the guidelines of the Chinese Council on Animal Care and approved by the General Hospital of Shenyang Military Region Animal Care Committee. For the experiments, $0.67 \mathrm{ml}$ of Allitride Injection (containing $10 \mathrm{mg}$ of DATS) was administered via a jugular vein cannula. Blood samples were taken from the rats at predetermined intervals and processed immediately.

Calculation of Pharmacokinetic Parameters

Blood drug concentration-time curves of DATS were evaluated using two-compartment analysis. The maximum blood concentration $\left(C_{\max }\right)$ and the time to
$C_{\max }\left(T_{\max }\right)$ were obtained directly from the individual blood concentration-time curves. The terminal half-life $\left(t_{1 / 2}\right)$ was obtained from weighted regression analysis of the blood concentration time curves during the terminal phase using the Drug and Statistics ver. 1.0 (DAS ver. 1.0) software. The area under the blood concentration-time curve up to the last quantifiable blood concentration $\left(\mathrm{AUC}_{\mathrm{lqc}}\right)$ was determined using the linear trapezoidal method.

\section{RESULTS}

Selectivity and Chromatography The separation achieved using the experimental conditions of the present assay for DATS and its main metabolites are presented in Fig. 1. Selectivity was indicated by the absence of any endogenous interference at the reten-
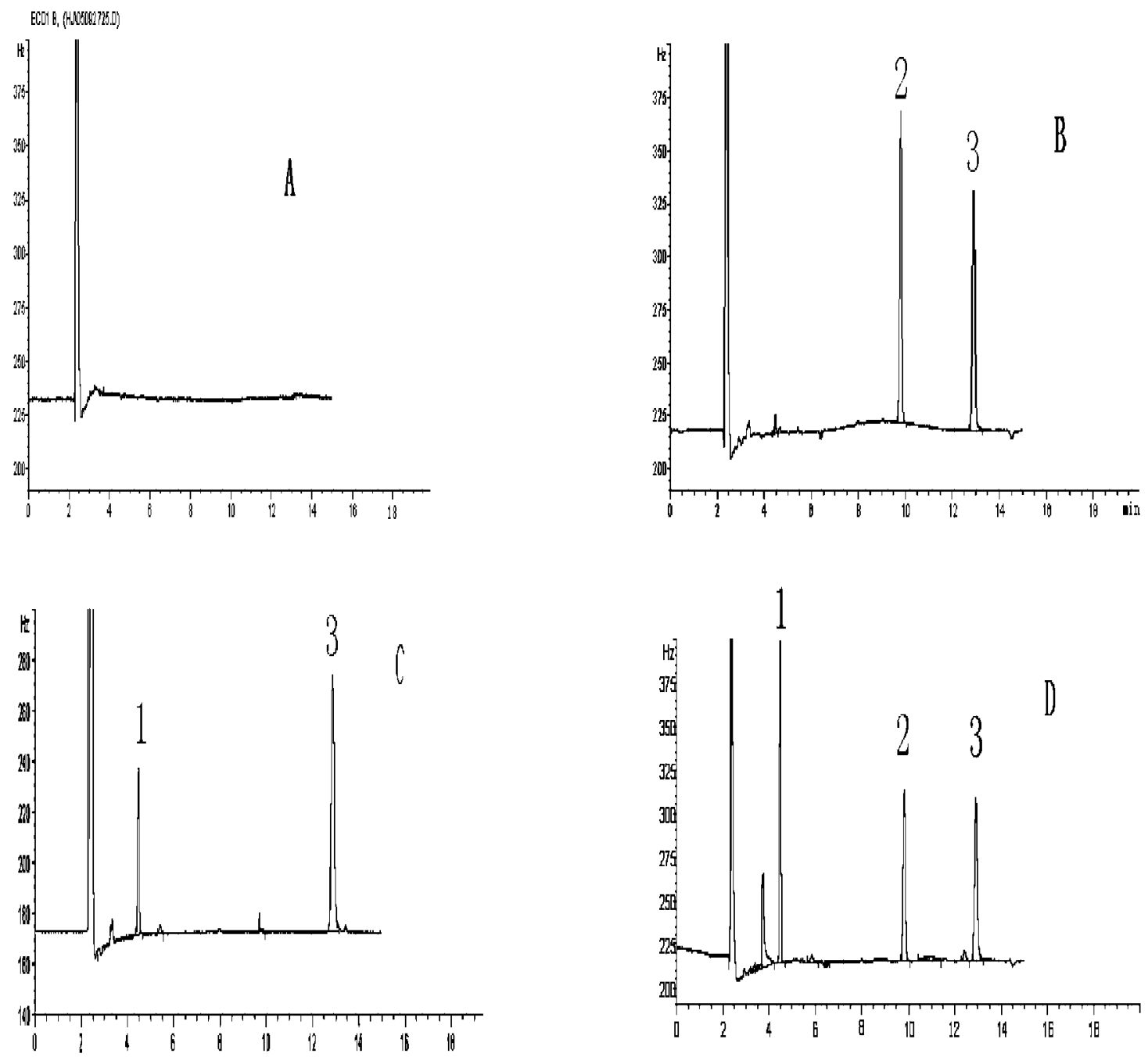

Fig. 1. Chromatograms of (A) Blank Rat Blood, (B) Blood Spiked with DATS $75 \mathrm{ng} / \mathrm{ml}$ and Spiked with $100 \mathrm{ng} / \mathrm{ml}$ Internal Standard (IS), (C) Blood Spiked with DADS $300 \mathrm{ng} / \mathrm{ml}$ and IS, (D) Blood Sample from a Rat 15 min after Administration Allitride Injection of $0.67 \mathrm{ml}$ (Containing about DATS $10 \mathrm{mg}$ ) via the Jugular Vein 1: DADS, 2: DATS, 3: IS. 
tion times of the peaks of interest as evaluated by chromatograms of control rat blood and blood spiked with the two compounds. The retention times for DATS, DADS, and IS were 9.8, 4.5, and $12.9 \mathrm{~min}$, respectively.

Identification of the major metabolite of DATS was accomplished by comparing its mass spectrum with those of authentic compounds available from a computerized spectral database (NIST ver. 6.0). The GC-MS chromatograms of DATS and DADS and the mass spectrum of DADS are presented in Figs. 2, 3 and 4 , respectively.

Linearity Six-point calibration curves for DATS on separate days were linear over the concentration range of $10-500 \mathrm{ng} / \mathrm{ml}$ and $0.2-20 \mu \mathrm{g} / \mathrm{ml}$. The equations for means $(n=3)$ of two standard curves are: $C=209.31 \mathrm{Ai} / \mathrm{As}-5.684, r^{2}=0.9989 ; C=$ 8.08Ai/As-0.094, $r^{2}=0.9993$, where $C, A i$, and $A s$ represent blood drug concentration, peak area of DATS, and IS, respectively.

\section{Lower Limit of Quantification Lower limit of}

quantification (LLOQs) as defined previously were $10 \mathrm{ng} / \mathrm{ml}$ for DATS. The accuracy of the method at the LLOQ was $105.4 \%$. The RSD of between- and within-day precisions was $10.8 \%$ and $6.60 \%$, respectively.

Recovery, Accuracy, and Precision The results from the validation of the method in rat blood are listed in Table 1. The method proved to be accurate and precise: accuracy at the three concentration levels ranged from $88.0 \%$ to $114.1 \%$ for DATS. The within- and between-day precision ranged from $2.83 \%$ to $7.51 \%$ and $5.29 \%$ to $10.8 \%$, respectively, for DATS. The absolute recoveries ranged from $83.4 \%$ to 93.9 $\%$.

Stability of DATS in Rat Blood The stability results of DATS in rat blood stored under different conditions are shown in Tables 2, 3, and 4.

Application of the Method To apply the developed and validated method, the pharmacokinetics of DATS was assessed in 6 rats. The plot of DATS mean blood concentrations as a function of time following

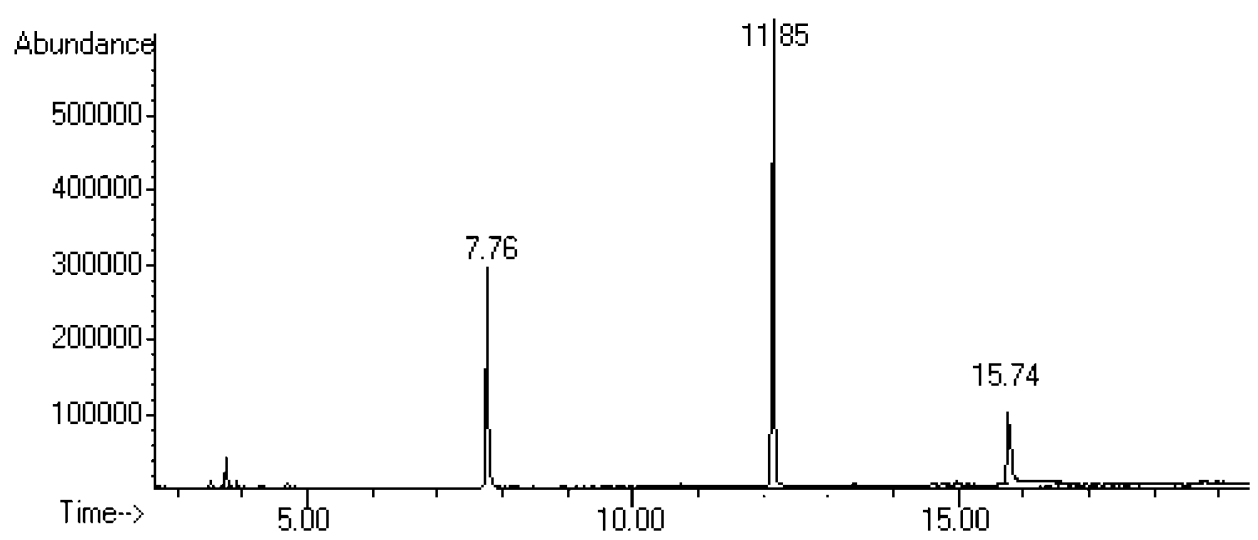

Fig. 2. GC-MS Chromatograms of DATS and Its Major Metabolite DADS (DADS: 7.76 min, DATS: 11.85 min)

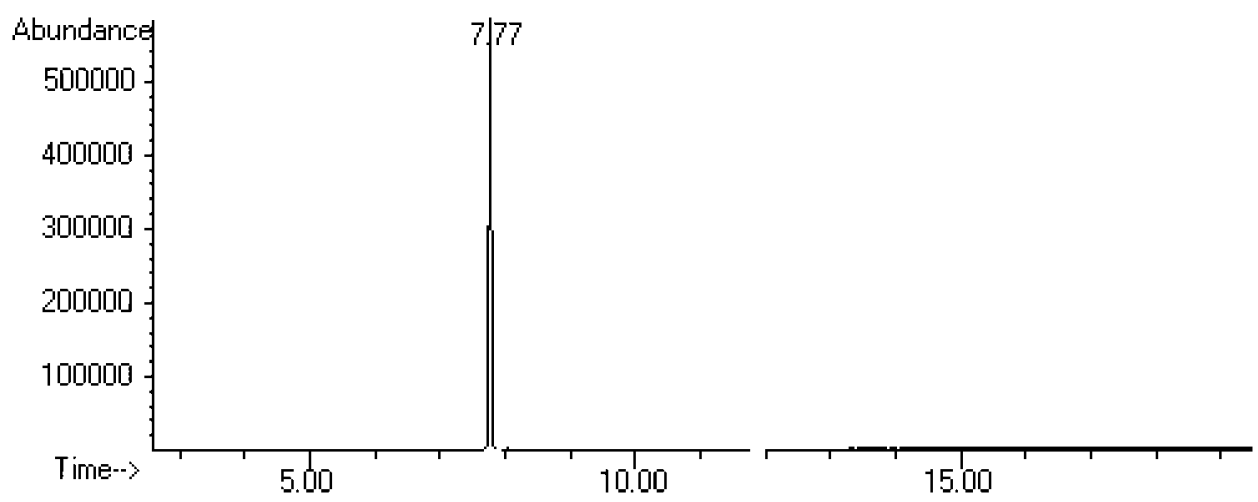

Fig. 3. GC-MS Chromatograms of DADS Standard (7.77 min) 
Table 1. Between-and Within-day Variability, Accuracy, and Recovery Rates for Determination of DATS

\begin{tabular}{ccccccc}
\hline \hline \multirow{2}{*}{$\begin{array}{c}\text { Concentration } \\
(\mathrm{ng} / \mathrm{ml})\end{array}$} & \multicolumn{2}{c}{ Between-day variability $(n=5)$} & \multicolumn{2}{c}{ Within-day variability $(n=5)$} & \multicolumn{2}{c}{ Recovery $(n=3)$} \\
\cline { 2 - 7 } Curve I & RSD (\%) & Accuracy $(\%)$ & RSD (\%) & Accuracy $(\%)$ & $\%$ & RSD $(\%)$ \\
10 & 10.8 & 105.4 & 6.60 & 114.1 & 85.3 & 10.1 \\
200 & 6.56 & 92.5 & 3.71 & 90.3 & 87.5 & 5.9 \\
400 & 5.35 & 91.9 & 2.83 & 88.0 & 83.5 & 4.8 \\
\hline Curve II $(\mu \mathrm{g} / \mathrm{ml})$ & & & & & & \\
0.2 & 6.74 & 110.0 & 7.51 & 105.0 & 83.4 & 6.3 \\
5 & 5.29 & 106.8 & 3.01 & 104.2 & 88.6 & 4.9 \\
20 & 5.74 & 112.5 & 6.02 & 109.5 & 93.9 & 1.7 \\
\hline
\end{tabular}

Table 2. Stability Results of DATS in Rat Blood Stored in Room Temperature $(n=3)$

\begin{tabular}{ccccc}
\hline \hline \multirow{2}{*}{$\begin{array}{c}\text { Time } \\
(\mathrm{h})\end{array}$} & \multicolumn{2}{c}{$\begin{array}{c}\text { Before precipitated by acetonitrile } \\
\text { Concentration } \\
(\mu \mathrm{g} / \mathrm{ml})\end{array}$} & $\begin{array}{c}\text { Degradation } \\
(\%)\end{array}$ & $\begin{array}{c}\text { Concentration } \\
(\mu \mathrm{g} / \mathrm{ml})\end{array}$ \\
\hline 0 & 1.06 & - & 1.06 & $\begin{array}{c}\text { Degradation } \\
(\%)\end{array}$ \\
3 & 0.01 & 99.5 & 1.05 & - \\
6 & 0 & 100 & 1.04 & 0.9 \\
12 & 0 & 100 & 1.03 & 1.9 \\
24 & 0 & 100 & 1.02 & 2.8 \\
\hline
\end{tabular}

Table 3. Stability Results of DATS in Rat Blood Stored at $-20^{\circ} \mathrm{C}(n=3)$

\begin{tabular}{|c|c|c|c|c|}
\hline \multirow{2}{*}{$\begin{array}{l}\text { Time } \\
\text { (d) }\end{array}$} & \multicolumn{2}{|c|}{ Before precipitation with acetonitrile } & \multicolumn{2}{|c|}{ After precipitation with acetonitrile } \\
\hline & $\begin{array}{l}\text { Concentration } \\
\quad(\mu \mathrm{g} / \mathrm{ml})\end{array}$ & $\begin{array}{c}\text { Degradation } \\
(\%)\end{array}$ & $\begin{array}{l}\text { Concentration } \\
\quad(\mu \mathrm{g} / \mathrm{ml})\end{array}$ & $\begin{array}{c}\text { Degradation } \\
(\%)\end{array}$ \\
\hline 0 & 1.06 & - & 1.06 & - \\
\hline 5 & 0.13 & 87.7 & 1.04 & 1.9 \\
\hline 10 & 0.12 & 95.3 & 1.02 & 3.8 \\
\hline 30 & 0.03 & 97.2 & 1.03 & 2.8 \\
\hline
\end{tabular}

Table 4. Stability Results of DATS after Three Freeze-thaw Cycles $(n=3)$

\begin{tabular}{ccc}
\hline \hline Freeze-thaw cycles & $\begin{array}{c}\text { Concentration } \\
(\mu \mathrm{g} / \mathrm{ml})\end{array}$ & $\begin{array}{c}\text { Degradation } \\
(\%)\end{array}$ \\
\hline 0 & 1.06 & - \\
1 & 0.11 & 89.6 \\
2 & 0.03 & 97.2 \\
3 & 0.01 & 99.1 \\
\hline
\end{tabular}

i.v. dosing is shown in Fig. 5 .

The pharmacokinetic parameters of DATS using two-compartmental analysis with DAS 2.0 are summarized in Table 5 .

\section{DISCUSSION}

It is difficult to determine DATS levels due to UV end-absorption, volatility, and instability. Levels can not be determined in vivo using common HPLC with a UV detector or with HPLC-MS. The level of DATS decreases markedly as the organic solvent evaporates to dryness under a s nitrogen tream. The stability results showed that DATS was so unstable that there was no time for centrifugation to separate the plasma from blood, and rat blood samples had to be added acetonitrile directly to stop degradation, and then extracted with hexane for sampling. DATS contains high electronegativity groups (-S-), which show a high response to ECD. The sensitivity can reach $1 \mathrm{ng} /$ 


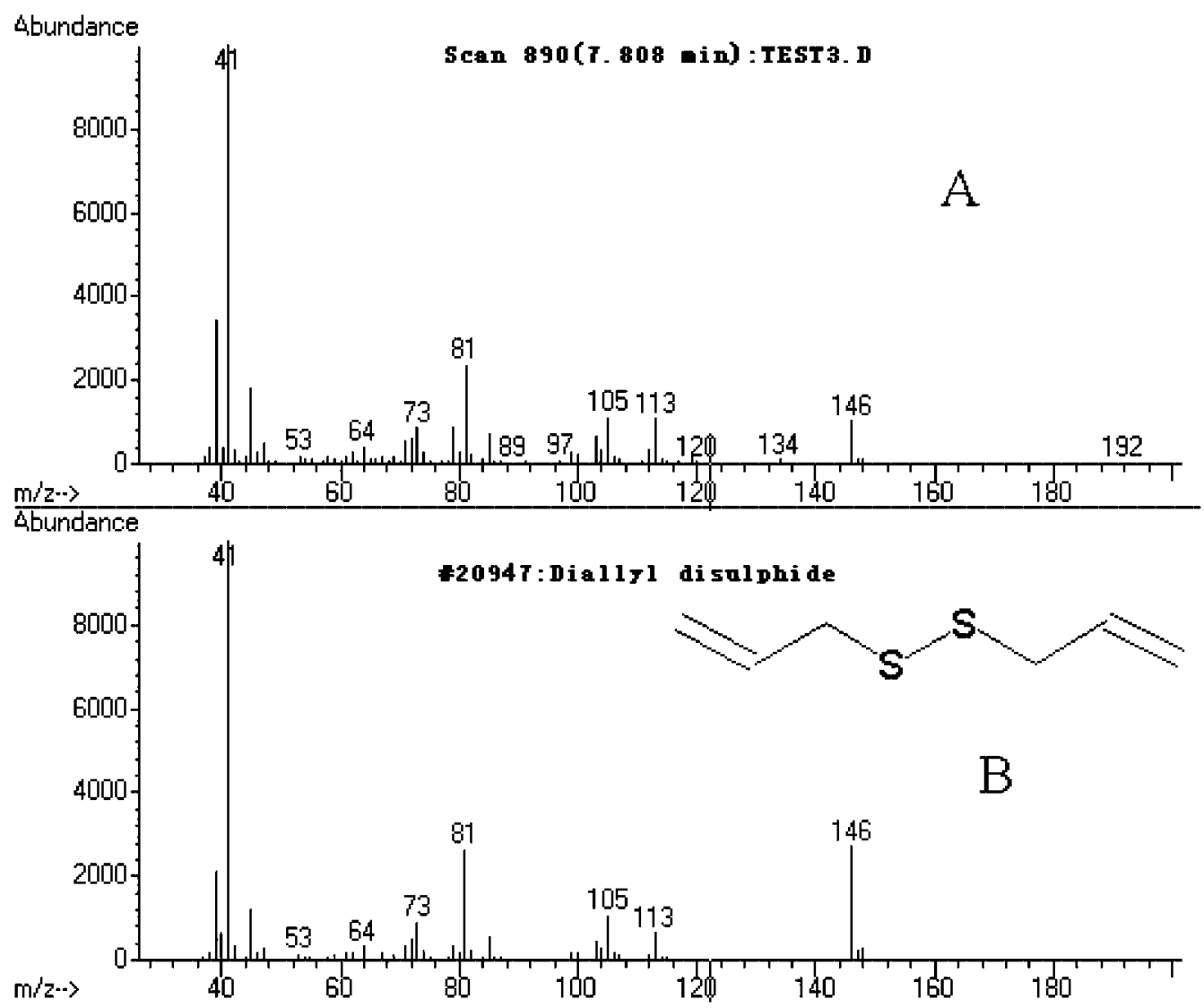

Fig. 4. Mass Spectrum of DADS (A: from Test, B: from Computerized Spectral Database)

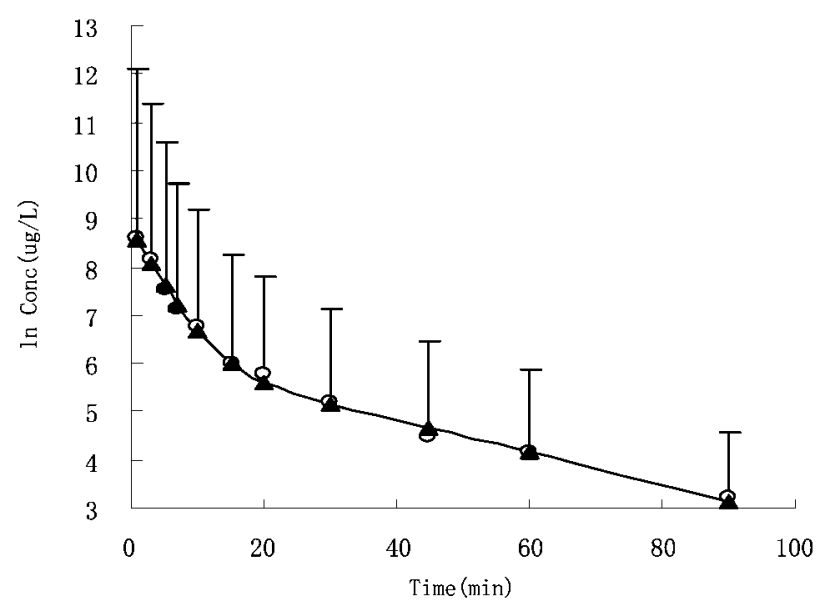

Fig. 5. Mean Concentration Logarithm-time Profile of DATS after Jugular Vein Cannula Administration of a Single 10 mg Dose of DATS to 6 Rats

Table 5. Pharmacokinetic Parameters Calculated Using DAS 1.0 after Jugular Vein Cannula Administration of DATS 0.5 ml (Containing about DATS $10 \mathrm{mg}$ )

\begin{tabular}{cccccccc}
\hline \hline Parameters & $\begin{array}{c}t_{1 / 2 \beta} \\
(\mathrm{min})\end{array}$ & $\begin{array}{c}\mathrm{Vd} \\
(\mathrm{l})\end{array}$ & $\begin{array}{c}\mathrm{CL} \\
(\mathrm{l} / \mathrm{min})\end{array}$ & $\begin{array}{c}\mathrm{AUC}_{0-90} \\
\left(\mathrm{ug} / 1^{*} \min \right)\end{array}$ & $\begin{array}{c}\mathrm{AUC}_{0-\infty} \\
\left(\mathrm{ug} / 1^{*} \min \right)\end{array}$ & $\begin{array}{c}T_{\max } \\
(\mathrm{min})\end{array}$ & $\begin{array}{c}C_{\max } \\
(\mu \mathrm{g} / \mathrm{l})\end{array}$ \\
\hline Mean & 20.8 & 8.0 & 0.3 & 34498.4 & 34981.7 & 1.0 & 5516.9 \\
\hline
\end{tabular}


$\mathrm{ml}$ or lower if DATS is directly added to hexane or other organic solvents. It is therefore possible to determine DATS levels even when it is diluted several fold during extraction using the present method.

The method described was established as a rapid analytical tool for pharmacokinetic study requiring short retention time, high precision and sensitivity, and small volumes of plasma for analyses. The parameters of the assay obtained in the course of validation are considered satisfactory for clinical application. A simple analytical procedure based on one-step extraction and a total run time of 15.0 min makes it possible to analyze some 50 samples per day.

Acknowledgments The authors thank the National Natural Sciences Foundation of China for financial support (Grant 30371782).

\section{REFERENCES AND NOTES}

1) Agarwal K. C., Med.Res. Rev., 16, 111-124 (1996).

2) Lau B. H. S., Tadi P. P., Nutr. Res., 10, 937948 (1990).

3) Yang C. S., Wang Z. Y., Hong J.Y., $A d v$. Exp. Med. Bio., 354, 113-122 (1994).

4) Bordia A., Verma S. K., Srivastava K. C., Prostaglandins Leukotrienes Essential Fatty
Acids, 55, 201-205 (1996).

5) Drouin E., Can. J. Gastroenterol., 13, 581583 (1999).

6) Salman H., Bergman M., Bessler H., Punsky I., Djaldetti M., Int. J. Immunopharmacol., 21, 589-597 (1999)

7) Yu T. H., Wu C. M., Liou Y. C., J. Agric. Food Chem., 37, 725-730 (1989).

8) Buckman J. D., Field L., J. Org. Chem., 32, 454-458 (1967).

9) Derbesy G., Harpp D. N, Tetrahedron Lett., 35, 5381-5384 (1994).

10) Lachmann G., Lorenz D., Radeck W., Steipe M., Arzneimittelforschung, 44, 734-743 (1994).

11) Arnault I., Haffner T., Siess M. H., Vollmar A., Kahane R., Auger J., J. Pharma. Biomed. Anal., 37, 963-970 (2005).

12) Rosen R. T., Hiserodt R. D., Fukuda E. K., Ruiz R. J., Zhou Z., Lech J., Rosen S. L., Hartman T. G., J. Nutr., 131, 968-971 (2001).

13) US Food and Drug Administration, "FDA Guidance for Bioanalytical Method Validation," Food and Drug Administration, Rockville, MD, 2001. 